\title{
Maintaining tricuspid valve competence in double discordance: a challenge for the paediatric cardiologist
}

\author{
P Acar, D Sidi, D Bonnet, Y Aggoun, P Bonhoeffer, J Kachaner
}

\begin{abstract}
Objectives-To establish the prevalence of tricuspid valve abnormalities in children with a double discordant heart (or congenitally corrected transposition of the great arteries); to study the influence of the loading conditions induced by various surgical interventions on the right and left ventricle in patients with double discordance and an abnormal tricuspid valve; and to propose a rational surgical approach.

Methods-Case notes were reviewed of 141 consecutive patients admitted in the first year of life with various types of double discordance (intact ventricular septum (group 1), ventricular septal defect (group 2), ventricular septal defect and pulmonary obstruction (group 3)). A study group of 62 patients with an abnormal tricuspid valve was selected by cross sectional echocardiography. These were followed up through palliative and open heart procedures with grading of tricuspid regurgitation.
\end{abstract}

Results-Tricuspid valve abnormalities were more common in groups 1 and 2 $(60 \%$ and $56 \%)$ than in group $3(31 \%)$. Preoperative tricuspid regurgitation was more common in group $2(90 \%)$ than in groups 1 and 3 (38\% and $36 \%)$. Ten patients in groups 1 and 2 died in the neonatal period with severe tricuspid regurgitation, associated with coarctation of the aorta in $60 \%$. Eight patients in group 1 had no surgery and are doing well, with a competent tricuspid valve. Palliative procedures were undertaken in 28 patients: 14 had pulmonary artery banding, which resulted in a decrease in tricuspid regurgitation, 12 in group 2 by reducing the pulmonary blood flow and two in group 1 by changing the septal geometry; 14 in group 3 had an aortopulmonary shunt, which induced tricuspid regurgitation in Service de cardiologie pédiatrique, Hôpital Necker/Enfants-malades, 149 Rue de Sèvres, 75743 Paris cedex 15, France

P Acar

D Sidi

D Bonnet

Y Aggoun

P Bonhoeffer

J Kachaner

Correspondence to: Dr Kachaner.

Accepted for publication 25 March 1998 sution 15 patients underwent conventional surgery, survived (mortality $33 \%$ ): eight with a tricuspid valve prosthesis and two with severe residual tricuspid regurgitation. However, tricuspid regurgitation decreased after anatomical correction (nine patients), restoring a systemic left ventricle and a subpulmonary right ventricle, even when the tricuspid valve was not repaired (five patients). Eight patients are doing well after anatomical correction (mortality 11\%).

Conclusions-Tricuspid valve function in double discordance with an abnormal tricuspid valve depends on the loading conditions of both ventricles and on the septal geometry. Interventions that increase right ventricular volume or decrease left ventricular pressure are likely to induce tricuspid regurgitation, while those that decrease right ventricular volume or increase left ventricular pressure are likely to improve tricuspid valve function. Repair of the tricuspid valve always failed when the right ventricle was left in a systemic position and always succeeded when the right ventricle was placed in a subpulmonary position. These results should be taken in to account when dealing with patients with double discordance and an abnormal tricuspid valve.

(Heart 1998;80:479-483)

Keywords: transposition of the great arteries; double discordance; double switch procedures; tricuspid valve; paediatric cardiology; congenitally corrected

transposition

Double discordance is a cardiac arrangementalso called "congenitally corrected transposition of the great arteries" - in which atrioventricular discordance is associated with ventriculoarterial discordance. It is a severe congenital heart defect, mainly because of associated cardiac malformations, particularly of the tricuspid valve. ${ }^{1-3}$ Tricuspid regurgitation is common, partly owing to malformations of the valve but also to bad loading conditions through being at systemic pressure behind the aorta or through having to accommodate increased blood flow during diastole when pulmonary blood flow is increased. ${ }^{48}$ Tricuspid regurgitation can also result from right ventricular failure with dilatation of the tricuspid valvar annulus.

The surgical management of tricuspid regurgitation in double discordance is a difficult challenge. Conventional repair or even replacement of the tricuspid valve while leaving the ventriculoarterial discordance uncorrected has a high mortality. ${ }^{9-11}$ This is why a new approach 
Table 1 Tricuspid valve (TV) anatomy and function

\begin{tabular}{lllllll}
\hline Group & $\begin{array}{l}\text { Total } \\
\text { population }\end{array}$ & $\begin{array}{l}\text { Study } \\
\text { population }\end{array}$ & $\begin{array}{l}\text { Dysplastic } \\
\text { TV }\end{array}$ & $\begin{array}{l}\text { Ebstein-like } \\
\text { TV }\end{array}$ & Preop TR & $\begin{array}{l}\text { Neonatal } \\
\text { deaths }\end{array}$ \\
\hline 1 & 30 & $18(60 \%)$ & 10 & 8 & $7(38 \%)$ & 5 \\
2 & 39 & $22(56 \%)$ & 13 & 9 & $20(91 \%)^{\star \star}$ & 5 \\
3 & 72 & $22(31 \%)^{\star}$ & 14 & 8 & $8(36 \%)$ & 0 \\
All & 141 & $62(44 \%)$ & 37 & 25 & 35 & 10 \\
\hline
\end{tabular}

${ }^{\star} \mathrm{p}<0.05$, group $3 v$ groups 1 and $2 ;{ }^{\star \star} \mathrm{p}<0.01$, group $2 v$ groups 1 and 3.

Preop TR, preoperative tricuspid regurgitation.

has recently been designed to restore double concordance by an arterial switch or intracardiac tunnel together with a Mustard or Senning procedure. ${ }^{12-14}$

The impact of this protocol, called "double switch procedure" or "anatomical repair," on tricuspid valve function is unknown. We therefore undertook a retrospective study on all patients with double discordance admitted to our institution over the last 20 years, looking at tricuspid valve anatomy and function in order (1) to assess the prevalence of tricuspid valve abnormalities and regurgitation in different anatomical and haemodynamic types of double discordance; and (2) to follow up these patients and look specifically at the effect of different surgical approaches on tricuspid regurgitation.

\section{Methods}

TOTAL POPULATION

The case notes of 141 consecutive patients with double discordance admitted between January 1975 and December 1995 were reviewed. All these patients were followed up from the first year of life, and $85 \%$ from the neonatal period. There were 89 boys and 52 girls. Three groups were identified, according to associated anomalies and pulmonary blood flow: group 1, normal pulmonary blood flow with intact ventricular septum $(n=30)$; group 2 , increased pulmonary blood flow with ventricular septal defect and pulmonary artery hypertension $(n=39)$; and group 3, decreased pulmonary blood flow with ventricular septal defect and pulmonary stenosis $(n=72)$. The atria were normally arranged in $95 \%$ of the patients in groups 1 and 2, but in only $75 \%$ in group 3, in which a mirror arrangement of the atria was found in $25 \%$. Only patients with tricuspid valve abnormality at their first examination were considered in this study.

\section{POPULATION WITH TRICUSPID VALVE}

ABNORMALITY

The anatomy of the tricuspid valve was assessed by cross sectional echocardiography. The tricuspid valve was found to be abnormal if the leaflets were thickened (dysplastic) or where there was additional downward displacement of the septal leaflet (Ebstein-like). Tricuspid regurgitation was assessed by angiography or colour Doppler imaging. Regurgitation was graded as usually described. ${ }^{15} 16$ Only significant tricuspid regurgitation (grade 3 or 4) was considered in this study. Sixty two of the 141 patients ( $44 \%$ of the global population) had tricuspid valve abnormality associated with double discordance (table 1) and form the study group. These 62 patients were followed up and were evaluated specifically before and after palliative or open heart repairs.

PALLIATIVE AND OPEN HEART PROCEDURES

Palliative surgery

Palliative surgery included either pulmonary artery banding in group 1 (to prepare the left ventricle for systemic function) and in group 2 (to prevent pulmonary hypertension and to decrease the volume overload in the lungs and through the tricuspid valve), or aortopulmonary shunts in group 3 (to improve hypoxaemia).

Conventional open heart surgery

Conventional open heart surgery, leaving the right ventricle under the aorta, was performed from 1978 to 1990; it consisted of closing the ventricular septal defect (group 2) or closing the ventricular septal defect and relieving the pulmonary obstruction by direct resection or, more often, by an external conduit between the left ventricle and the pulmonary artery (group 3).

\section{Anatomical correction}

From 1991, anatomical correction was performed with the aim of restoring normal ventriculoarterial connections to the right ventricle in the subpulmonary position and to the left ventricle in the subaortic position. This was achieved by a double switch operation combining an atrial switch (Senning or Mustard procedure) with an arterial switch-after preparation of the left ventricle in group 1 -together with closure of the ventricular septal defect in group 2. The repair of the ventriculoarterial discordance in group 3 was achieved by an intracardiac tunnel between left ventricle and aorta, associated with a right ventricle to pulmonary artery conduit (Rastelli procedure). The tricuspid valve was repaired or replaced whenever necessary.

\section{STATISTICAL ANALYSIS}

We compared the prevalence of tricuspid valve abnormality and tricuspid regurgitation in the three groups of double discordance patients using the $t$ test (differences were considered significant at a probability ( $p)$ value of $<0.05$ ). Comparison between conventional surgery and anatomical correction was also made using the $t$ test.

\section{Results}

PREVALENCE OF TRICUSPID VALVE ABNORMALITY The tricuspid valve was abnormal in $44 \%$ of the total double discordance group, with different prevalences in the three groups: $60 \%$ in group 1,56\% in group 2, and $31 \%$ in group $3(\mathrm{p}<0.05$ between group 3 and groups 1 and 2) (table 1). The tricuspid valve was dysplastic in $60 \%$ and Ebstein-like in $40 \%$, but there was no difference in the type of tricuspid valve between the three groups.

PREOPERATIVE TRICUSPID REGURGITATION Preoperative tricuspid regurgitation was observed in 35 of the 62 patients (56\%) with double discordance and tricuspid valve abnormality. 
Table 2 Palliation in 28 patients with tricuspid valve abnormalities

\begin{tabular}{llll}
\hline Group & Patients $(n)$ & PA banding & AP shunt \\
\hline 1 & 13 & $2^{\star}$ & 0 \\
2 & 17 & $12^{\star}$ & 0 \\
3 & 22 & 0 & $14 \dagger$ \\
All & 52 & 14 & 14
\end{tabular}

^Decrease in tricuspid regurgitation in all patients. †Increase in tricuspid regurgitation in two patients. $\mathrm{AP}$, aortopulmonary shunt; PA pulmonary artery.

The prevalence of tricuspid regurgitation was much higher in group $2(90 \%)$ than in group 3 $(36 \% ; \mathrm{p}<0.001)$ or group $1(38 \% ; \mathrm{p}<0.001)$ (table 1).

\section{EARLY PREOPERATIVE MORTALITY}

Follow up data refer to the time of writing.

Ten of the 62 patients $(26 \%)$ died before any surgery (five in group 1 and five in group 2) (table 1). Aortic coarctation was associated with neonatal death in $60 \%$. Therefore, fifty two patients with double discordance and abnormal tricuspid valve survived from the neonatal period and were followed up: eight are alive at 10 (SD 4) years without any surgery (all in group 1), 20 survivors had a palliative procedure only, and 24 patients had an open heart repair, following a palliative procedure in eight cases.

PALLIATIVE SURGERY

Twenty eight patients had palliative surgery (table 2).

Pulmonary artery banding

Fourteen patients had pulmonary artery banding. Two patients in group 1 with tricuspid regurgitation had pulmonary artery banding at four and six years to prepare the left ventricle for an anatomical correction. Diminished tricuspid regurgitation began in the early postoperative period and continued until the time

Table 3 Open heart surgery in 24 patients

\begin{tabular}{|c|c|c|c|c|c|}
\hline Group & $\begin{array}{l}\text { Previous } \\
\text { operation }\end{array}$ & $\begin{array}{l}\text { Tricuspid } \\
\text { surgery }\end{array}$ & Associated surgery & $\begin{array}{l}\text { Early } \\
\text { outcome }\end{array}$ & $\begin{array}{l}\text { Final } \\
\text { status }\end{array}$ \\
\hline \multirow[t]{5}{*}{1} & No & TVR & - & - & Alive \\
\hline & No & TVR & - & - & Alive \\
\hline & No & TVR & - & - & Alive \\
\hline & РAB & Repair & Senning + ASO & - & Alive \\
\hline & PAB & Repair & Senning + ASO & - & Alive \\
\hline \multirow[t]{9}{*}{2} & No & TVR & VSDc & Death & - \\
\hline & PAB & Repair & VSDc & TVR & Alive \\
\hline & VSDc & TVR & - & - & Alive \\
\hline & PAB & Repair & VSDc & TR incr & Alive \\
\hline & VSDc & TVR & - & - & Death \\
\hline & No & TVR & VSDc & - & Death \\
\hline & No & TVR & VSDc & - & Death \\
\hline & PAB & TVR & VSDc & - & Alive \\
\hline & PAB & Repair & Mustard + ASO + VSDc & - & Alive \\
\hline \multirow[t]{10}{*}{3} & Shunt & TVR & LV-PAc + VSDc & - & Alive \\
\hline & No & TVR & LV-PAc + VSDc & - & Alive \\
\hline & No & Repair & $\mathrm{LV}-\mathrm{PAc}+\mathrm{VSDc}$ & TR incr & Alive \\
\hline & No & TVR & LV-PAc + VSDc & Death & - \\
\hline & No & - & Mustard + Rastelli & - & Alive \\
\hline & No & - & Mustard + Rastelli & - & Alive \\
\hline & No & - & Mustard + Rastelli & Death & - \\
\hline & No & - & Mustard + Rastelli & - & Alive \\
\hline & No & Repair & Senning + Rastelli & - & Alive \\
\hline & Shunt & - & Senning + Rastelli & - & Alive \\
\hline
\end{tabular}

ASO, arterial switch operation; LV-PAc, left ventricle-pulmonary artery conduit; PAB, pulmonary artery banding; TR incr, tricuspid regurgitation increased; TVR, tricuspid valve replacement; VSDc, ventricular septal defect closure. of the anatomical correction, which was performed two and three years after the pulmonary banding. Twelve patients in group 2 with tricuspid regurgitation underwent pulmonary artery banding at (mean (SD)) 6 (4) months. Tricuspid regurgitation was significantly reduced in all. Eight of these 12 patients are still alive with a pulmonary band only and a competent tricuspid valve, at a follow up of 5 (3) years. The other four patients had open heart surgery.

\section{Aortopulmonary shunt}

Fourteen patients with tricuspid valve abnormality without tricuspid regurgitation had an aortopulmonary shunt at 10 (6) months. Two of these (14\%) developed significant postoperative tricuspid regurgitation and had open heart surgery two and three years later. The other 12 patients are alive with one or two aortopulmonary shunts and a competent tricuspid valve at follow up of 4 (3) years.

OPEN HEART SURGERY

Twenty four patients had open heart surgery (table 3).

\section{Conventional repairs}

Fifteen patients (three in group 1, eight in group 2, four in group 3) had conventional repairs leaving the right ventricle in a systemic position. Three patients in group 1 developed significant tricuspid regurgitation and had a tricuspid valve replacement at 11,15 , and 28 years. The postoperative course was simple and the patients are alive one, two, and four years after operation without right ventricular dysfunction.

Eight patients in group 2 underwent ventricular septal defect closure either after pulmonary artery banding (three patients) or as an early primary procedure (five patients). In six of these, tricuspid surgery was also undertaken: tricuspid valve repair was attempted in two patients, with poor results in both (residual tricuspid regurgitation led to tricuspid valve replacement in one of these); tricuspid valve replacement was primarily achieved in four patients, with three postoperative deaths. The remaining two patients in group 2 with abnormal but competent tricuspid valves developed significant tricuspid regurgitation after closure of ventricular septal defects: both underwent tricuspid valve replacement with one postoperative death and one survivor after four years.

Four patients in group 3 underwent closure of ventricular septal defects with a left ventricle to pulmonary artery conduit, either as a primary repair (three patients) or after a previous aortopulmonary shunt (one patient). In three of these, the tricuspid valve was replaced (one early death); the fourth had a tricuspid valve repair and is alive two years later, but with severe residual tricuspid regurgitation.

\section{Anatomical correction}

Nine patients (two in group 1, one in group 2, six in group 3) had an anatomical repair. 
Two patients in group 1 underwent an arterial switch together with a Senning procedure three and four years after pulmonary artery banding (ventricular preparation) without any tricuspid valve repair. The postoperative course was uneventful and they are alive one and two years later without any tricuspid valve dysfunction.

One patient in group 2 had an arterial switch together with a Mustard procedure and a tricuspid valve repair nine years after pulmonary banding. This patient is alive two years later without tricuspid valve dysfunction.

Six patients in group 3 underwent anatomical correction at 6 (4) years: a Rastelli procedure in all, a Mustard procedure in four, and a Senning procedure in two, associated with tricuspid valve repair in one. There was one death from compression of the right ventricle to pulmonary artery conduit in the heart; this child had a normal atrial arrangement but dextrocardia. The other five patients are alive at 3 (2) years with no tricuspid regurgitation.

SURGICAL MORTALITY

Mortality from conventional surgery (five of 15 patients) was $33 \%$, while mortality from anatomical correction (one of nine patients) was $11 \%(\mathrm{p}<0.05)$.

\section{Discussion}

Some limitations need to be pointed out. The study was retrospective over 20 years, and it may be considered invalid to compare surgical mortality in two historical series (conventional surgery before 1990 and anatomical repair after 1990). However, the study has strength in the large number of patients followed up from early life.

The prevalence of tricuspid valve abnormalities in the group as a whole was $44 \%$. This is lower than the $50-90 \%$ reported in anatomical studies. ${ }^{39}$ The difference may be explained by the way we identified the lesions: only significant abnormalities of the tricuspid valve diagnosed by cardiac imaging were included.

A relation between the degree of tricuspid regurgitation and the volume of pulmonary blood flow through the valve was suggested by Lundstrom et al, who found a very low incidence of tricuspid regurgitation in a series of double discordant patients with pulmonary obstruction and decreased pulmonary flow. ${ }^{17}$ We also found that tricuspid regurgitation in patients with tricuspid valve abnormalities was much more common in the neonatal period when double discordance was associated with increased pulmonary flow $(90 \%)$ than with normal or decreased pulmonary flow (38\% and $36 \%$, respectively). This difference may be related to the embryological development of the tricuspid valve as our study showed more tricuspid abnormalities in double discordance without pulmonary obstruction $(60 \%$ in group 1 and $51 \%$ in group 2) than with pulmonary obstruction ( $31 \%$ in group 3 ). However, part of this difference is very likely to be functional, since only eight of 22 patients with tricuspid valve abnormalities in group 3 (that is, with low pulmonary blood flow) had neonatal tricuspid regurgitation, whereas almost all patients with increased pulmonary blood flow (group 2) did have neonatal tricuspid regurgitation. Furthermore, we found a consistent improvement in the tricuspid regurgitation after pulmonary artery banding, contrasting with a significant incidence of tricuspid valve dysfunction after construction of an aortopulmonary shunt. This could have been due to excessive flow through the systemic tricuspid valve resulting from the left to right shunt through the ventricular septal defect in group 2, or through the aortopulmonary shunt in group 3 .

As have others, ${ }^{10} 11$ we have observed a high incidence of tricuspid regurgitation induced by the conventional surgical protocols. We do not think this is a result of a direct lesion of the valvar system during the operation, but rather that the fall in left ventricular pressure after closure of the ventricular septal defect may have modified the geometry of the septum, causing attraction of the septal leaflet of the tricuspid valve towards the left ventricle and distorting the other leaflets, especially if the septal leaflet was attached to the septum as in Ebstein's malformation. Two of our patients with an Ebstein-like malformation developed severe tricuspid regurgitation after conventional surgery. One suspects that this could have been avoided by maintaining a high pressure in the left ventricle by leaving the pulmonary artery banding. This option would also have allowed a subsequent "anatomical" correction of the double discordance. The same geometric explanation would fit with the decrease in tricuspid regurgitation in group 1, when left ventricular pressure is increased by pulmonary artery banding, pushing the septal leaflet into the right ventricle.

Our study confirms the high mortality from conventional procedures in double discordance reported by the Alabama group. ${ }^{18}$ Dysfunction of the systemic right ventricle appears to be the major postoperative issue. Tricuspid valve repair always failed when the right ventricle was left under high aortic afterload. ${ }^{19-21}$ Conversely, repair of the Ebstein tricuspid valve in doubly concordant hearts with a low pressure right ventricle is usually effective. ${ }^{22}$ Our study confirms the beneficial effects of anatomical correction on tricuspid valve function. The small number of patients and the short postoperative follow up do not allow us to recommend this kind of surgery as an elective way of managing any kind of double discordance, regardless of the status of the tricuspid valve and its function. But we are not very far from making such a recommendation, since other groups have also reported excellent results of anatomical repair in double discordance. $.^{13} 23-25$

In the meantime, we think that the anatomical repair strategy is strongly supported by our results in all patients with double discordance and severe tricuspid valve abnormality or tricuspid regurgitation. Most of the patients with ventricular septal defect can be treated by a "double switch" plus ventricular septal defect closure unless the pulmonary valve is leaking because of previous and prolonged pulmonary artery banding. In double discordance with an intact septum, anatomical correction can only 
be offered to high pressure left ventricles. This is the case in the neonatal period. It is sometimes also the case in older children with high pulmonary wedge pressures owing to the tricuspid regurgitation and adapted hypertrophic ventricular walls. In the remaining cases, anatomical repair can only be performed after "retraining" the left ventricle by pulmonary artery banding. ${ }^{26}$ In double discordance with ventricular septal defect and pulmonary stenosis, the latter lesion prevents us from switching the great vessels and the procedure is more complex. One has to insert an intracardiac patch tunnel between the left ventricle and the aorta through the ventricular septal defect and restore right heart continuity either directly or by a conduit.

\section{CONCLUSIONS}

We propose that patients with double discordance and tricuspid valve abnormalities should be managed as follows. (1) Patients with a competent tricuspid valve have to be protected from the development of significant tricuspid regurgitation. One should therefore avoid using aortopulmonary shunts which increase flow through the valve (group 3), or conventional repairs which modify the septal geometry by decreasing the left ventricular pressure. (2) Patients with significant tricuspid regurgitation should be treated either by pulmonary artery banding, to decrease the flow through the valve (group 2) or to increase the left ventricular pressure (group 1), or by anatomical correction. Restoring a right ventricle in a subpulmonary position is more effective at ensuring tricuspid valve competence than any direct attempt to repair the tricuspid valve as long as this valve remains under systemic pressure. (3) Our study does not reveal how we should manage patients with double discordance without tricuspid valve abnormality.

1 Van Praagh R. What is congenitally corrected transposition? N Engl f Med 1970;282:1097-8.

2 Schiebler GL, Edwards JE, Burchell HB, et al. Congenitally corrected transposition of the great vessels: a study of 33 cases. Pediatrics 1961;27:851-88

3 Allwork SP, Bentall HH, Becker AE, et al. Congenitally corrected transposition of the great arteries: morphologic studies of 32 cases. Am f Cardiol 1976;38:910-23.
4 Westerman GR, Lang GP, Castaneda AR, et al. Corrected transposition and repair of associated intra-cardiac defects. transposition and repair of associated in

5 Shem-Tov A, Deusch V, Yahini JH, et al. Corrected transposition of the great arteries, a modified approach to the clinical diagnosis in 30 cases. Am f Cardiol 1971;27:99-113.

6 De Albuquerque A, Rigby ML, Anderson RH, et al. The spectrum of atrio-ventricular discordance. A clinical study. Br Heart f 1984;51:498-507.

7 Friedberg DZ, Nadas AS. Clinical profile of patients with congenital corrected transposition of great arteries. A study of 60 cases. $N$ Engl F Med 1970;282:1053-9.

8 Acar P, Bonnet D, Aggoun Y, et al. Doubles discordances avec communication interventriculaire et obstacle pulmonaire: étude de 72 cas. Arch Mal Coeur 1997;90:625-9.

9 Hwang B, Bowman F, Malm J, et al. Surgical repair of congenitally corrected transposition of the great arteries.

10 Williams WG, Suri R, Shindo G, et al. Repair of major intracardiac anomalies associated with atrio-ventricular discordance. Ann Thorac Surg 1981;31:527-32.

11 Dubost C, Chauvaud S, Blondeau P, et al. Discordances atrio-ventriculaires. Résultats de 34 opérés. Arch Mal Coeur $1981 ; 74: 255-63$

12 Yamagishi Y, Imai Y, Hoshino S, et al. Anatomic correction of atrio-ventricular discordance. $\mathcal{F}$ Thorac Cardiovasc Surg 1993;105:1267-76.

13 Imai Y, Sawatari K, Hoshimo S, et al. Ventricular function fter anatomic repair in patients with atrio-ventricular discordance. F Thorac Cardiovasc Surg 1994;107:1272-83.

14 Di Donato R, Troconis C, Marino B, et al. Combined Mustard and Rastelli operations: an alternative approach for repair of associated anomalies in congenitally corrected transposition in situs inversus (IDD). F Thorac Cardiovasc Surg 1992;104:1246-8.

15 Baron MG. Angiographic evaluation of valvular insufficiency. Circulation 1971;43:599-605.

16 Miyatake K, Okamoto M, Kinoshita N, et al. Clinical applications of a new type of real time two-dimensional Doppler cations of a new type of real time two-dimensional Dopp
flow imaging system. Am 7 Cardiol 1984;54:857-68.

17 Lundstrom U, Bull C, Wyse R, et al. The natural and unnatural history of congenitally corrected transposition. Am $\mathcal{f}$ Cardiol 1990;65:1222-9.

18 McGrath LB, Kirklin JW, Blackstone EH, et al. Death and other events after cardiac repair in discordant atrioventricular connection. F Thorac Cardiovasc Surg 1985;90:711-28.

19 Anderson K, Danielson G, McGoon D, et al. Ebstein's anomaly of the left-sided tricuspid valve. Circulation 1978; 58(suppl I):I.87-91.

20 Schiebler GL, Gravenstein JS, Van Mierop LHS. Ebstein's anomaly of the tricuspid valve. Translation of the original description with comments. Am f Cardiol 1968;22:867-73.

21 Kachaner J, Piéchaud JF, Fermont L, et al. La valve auriculo-ventriculaire systémique dans les discordances atrio-ventriculaires avec discordance ventriculo-artérielle. L'Information Cardiologique (Paris) 1980;3:33-6.

22 Carpentier A, Chauvaud S, Macé L, et al. A new reconstructive operation for Ebstein's anomaly of the reconstructive operation for Ebstein's anomaly of the
tricuspid valve. $\mathcal{F}$ Thorac Cardiovasc Surg 1988;96:91-101.

23 Yagihara T, Kishimoto H, Isobe F, et al. Double switch operation in cardiac anomalies with atrioventricular and ventriculoarterial discordance. $\mathcal{F}$ Thorac Cardiovasc Surg 1994;107:351-8.

24 Stümper O, Wright JG, De Giovanni JV, et al. Combined atrial and arterial switch procedure for congenital corrected transposition with ventricular septal defect. $\mathrm{Br}$ Heart $f$ 1995;73:479-82.

25 Karl TR, Weintraub RG, Brizard CP, et al. Senning plus arterial switch operation for discordant (congenitally corrected) transposition. Ann Thorac Surg 1997;64:495-502.

26 Bonhoeffer P, Carminati M, Parenzan L, et al. Non-surgical left ventricular preparation for arterial switch in transposition of the great arteries. Lancet 1992;340:549-50. 